\title{
Mental wellness in Canada's Aboriginal communities: striving toward reconciliation
}

\author{
Patricia Boksa, PhD; Ridha Joober, MD, PhD; Laurence J. Kirmayer, MD
}

With the presentation in Ottawa this spring of the report from the Truth and Reconciliation Commission (TRC) of Canada on Indian residential schools, the well-being of Canada's Aboriginal peoples took centre stage for a few days in the media and minds of the Canadian public. The TRC documented key historical issues that have contributed to major mental health disparities in Canada's indigenous population and pointed the way toward a larger process of national reconciliation. ${ }^{1}$ Because JPN is the official journal of the Canadian College of Neuropsychopharmacology, a Canadian society devoted to understanding mental health and disease, we are taking the opportunity with this editorial to keep the discussion going forward by highlighting the mental wellness of Aboriginal peoples in Canada. We present a brief historical background of some of the factors recognized as contributing to current mental health challenges faced by the Aboriginal population and end with some suggestions on how mental health professionals might contribute to the reconciliation process. Although much of what we discuss in this editorial has been written before, it bears repeating to engage our readers. In addition to their importance in the Canadian context, many of the issues we discuss are relevant to indigenous peoples in other countries.

\section{Historical overview}

Aboriginal people make up about $4 \%$ of the current population of Canada and comprise First Nations (60\%), Métis (33\%) and Inuit peoples (4\%). More than half of Aboriginal people live in Canadian cities, with the remainder living largely in rural or remote small communities. There is substantial cultural diversity among Aboriginal peoples in Canada; for example, First Nations comprise more than 600 major bands speaking 55 different languages from 11 major language groups. Historically, First Nations are derived from peoples with ancient roots in Canada. Ancestors of all North American indigenous peoples date back to 13500 years ago, while archeological records clearly date numerous First Nations settlements in Canada originating as far back as 9000 to 10000 years. By 500-1000 CE, First Nations peoples had established trade routes across what is now Canada, while the
Inuit, descendants of the Thule in Alaska, migrated across the Arctic starting from around $1000 \mathrm{CE}$.

Starting in the sixteenth century, European colonization had catastrophic effects on the indigenous peoples of North America (for a review, see Kirmayer and colleagues ${ }^{2}$ ). About $90 \%$ of the population died by the mid-1850s due largely to the introduction of infectious diseases, but also due to warfare and forced displacement. Aboriginal persons remaining in Canada were subjected to systematic oppression by the Canadian government designed to "civilize," assimilate and eliminate their cultures. The creation of Indian reserves aimed to confine Aboriginal people to small settlements while appropriating their lands. The locations of these communities were decided by government and commercial interests with the main purpose of freeing more desirable land for the use of European settlers. The Indian Act of 1876 formalized the reserve system and made "status" Indians wards of the state, with the federal government financing and imposing structures for band administration, education and health care. The explicit purpose of this legislation was to eliminate indigenous cultures by inculcating European values, as illustrated by the following quotation from an 1876 Department of Indian Affairs report:

Our Indian legislation generally rests on the principle, that the aborigines are to be kept in a condition of tutelage and treated as wards or children of the State. ...the true interests of the aborigines and of the State alike require that every effort should be made to aid the Red man in lifting himself out of his condition of tutelage and dependence, and that is clearly our wisdom and our duty, through education and every other means, to prepare him for a higher civilization by encouraging him to assume the privileges and responsibilities of full citizenship. ${ }^{3}$

These views were in line with the colonial doctrines prevalent in other parts of the world during that historical epoch.

From 1883 until the mid-1980s, the Indian residential school system was another means used to inculcate EuroChristian values, this time targeting Aboriginal children. The aim of this educational system was put bluntly by Duncan Campbell Scott, head of the Department of Indian Affairs from 1913-1932:

Correspondence to: P. Boksa, Douglas Institute - Research, Pavillion Perry, Rm. E-2110, 6875 LaSalle Blvd., Verdun QC H4H 1R3; patricia.boksa@mcgill.ca

DOI: $10.1503 / j p n .150309$ 
I want to get rid of the Indian problem. I do not think as a matter of fact, that the country ought to continuously protect a class of people who are able to stand alone... Our objective is to continue until there is not a single Indian in Canada that has not been absorbed into the body politic and there is no Indian question, and no Indian Department, that is the whole object of this Bill. ${ }^{4}$

Under Scott, in 1920 it became mandatory for every Indian child between the ages of 7 and 15 years to attend school. Since many reserves in remote areas had no schools, this meant the residential schools, which approximately 150000 Aboriginal youth attended over several generations. Children were often removed from their communities; isolated from their families, ways of living and language; and expected to take on a completely foreign demeanor in an atmosphere of strict regimentation. The schools were often sorely underfunded and plagued by overcrowding, poorly trained staff, poor sanitation and heating, and inadequate nutrition and health care. Lack of human warmth and physical abuse as enforcement were standard, while many children also experienced outright neglect and psychological and sexual abuse. This large-scale removal of children disrupted family and community structures, so that cultural tradition and values could not be passed on, often leading to intergenerational loss of parenting skills and fragility in forming attachments. The final report of the TRC concluded that Canada had committed cultural genocide in its dealings with Aboriginal peoples. ${ }^{1}$

\section{Current challenges and strengths}

The historical trauma of the Indian residential school system has had ongoing intergenerational effects on the psychological well-being of Aboriginal communities. ${ }^{5}$ For example, higher rates of depressive symptoms, suicidal thoughts and attempts, and childhood abuse and neglect are reported among adults with a parent or grandparent who attended an Indian residential school in Canada (termed IRS offspring) than in those whose parents and grandparents did not. ${ }^{6-8}$ The IRS offspring reported greater depressive symptoms associated with stressors, such as childhood adversity, adult trauma and perceived discrimination, suggesting an enhanced sensitivity to such stressors. ${ }^{6}$ Additional challenges include higher rates of illicit and prescription drug use and abuse that have been observed among Aboriginal youth and adults compared with non-Aboriginal Canadian populations. ${ }^{9-11}$ Social determinants of health, such as poverty, unemployment, housing and food security, social exclusion and discrimination, almost certainly play a role in the mental health challenges faced by Aboriginal peoples given that they remain, on the whole, among the poorest and most socially disadvantaged people in Canada. However, identifying these enduring social structural and historical causes of adversity in Aboriginal communities does not obviate the need to address current mental health. As noted in Feathers of Hope, a First Nations Youth Action Plan ${ }^{12}$ from Ontario, labelling mental health issues as social issues is sometimes used as an unacceptable excuse for neglecting to provide adequate services.
While certain historical realities have affected and continue to affect virtually all Aboriginal peoples in Canada, as with any diverse population, there are variations in rates of psychiatric disorders and symptomatology among individual communities. Research points to factors such as cultural identity and overall community self-determination and vitality as potentially important resiliency factors accounting for some of these variations. For example, while overall rates of suicide and suicidal ideation for Aboriginal youth are higher than in the general population of Canada, ${ }^{13,14}$ Chandler and Lalonde ${ }^{15}$ found wide variations in rates of completed suicide in a study of 80 First Nations bands in British Columbia (BC). Most notably, these rates of suicide among the various $\mathrm{BC}$ communities correlated strongly with an index of "cultural continuity" or local control based on the presence of several community factors, including self-government; involvement in land claims; and band control of education, health services, cultural facilities, and police and fire services. ${ }^{15}$ In a recent study examining drug misuse among urban Aboriginal adults living in Edmonton, Canada, Currie and colleagues ${ }^{11}$ found that enculturation, defined as "the degree to which Aboriginal peoples identify with, feel a sense of pride for, and integrate the values and norms of their Aboriginal heritage culture," was associated with reduced illicit and prescription drug problems. In agreement with these findings, the recently released First Nations Mental Wellness Continuum Framework — jointly developed by the First Nations and Inuit Health Branch of Health Canada, the Assembly of First Nations, and indigenous mental health leaders from various First Nations - highlights culture and the use of culturally specific holistic interventions incorporating indigenous knowledge as a cornerstone to achieving individual, family and community mental wellness. ${ }^{16}$

Across the country, some Aboriginal communities are devising innovative and effective mental wellness programs based on a strong sense of community and family, and often integrating elements of Western medicine with local cultural approaches to resilience, such as land-based and other traditional activities. Yet a major challenge to achieving mental wellness for many Aboriginal people is a general lack of appropriate and engaging mental health services. With the current jurisdictional division of Aboriginal health care between federal and provincial governments, there is a lack of dedicated long-term funding for mental health services. Funding is often project-based and time limited, and sustainability is a continual challenge. Many smaller, remote communities have limited or no access to mental health services. There is a dearth of trained mental health workers of Aboriginal origin and a high turnover of non-Aboriginal health workers leading to a lack of continuity of services and a lack of connection to specialized services for persons with severe mental illness or excessively long wait lists. Stigma and discrimination remain as major barriers to accessing mental health services. In mainly non-Aboriginal mental health settings, the values and traditions of Aboriginal persons may be poorly understood and their concepts of wellness and ways of knowing undervalued. Thus services may be inadequate or inappropriate owing to a lack of culturally competent and knowledgeable mental health care providers. 


\section{Mental health and the reconciliation process}

What can mental health professionals reading this editorial do to contribute to bridging the rift wrought by history and supporting mental wellness for Aboriginal communities? In fact, there are many opportunities for action by practitioners, whatever their interests, cultural backgrounds, resources and locations. The following are some suggestions.

- Take opportunities to talk with people of Aboriginal origin to learn about their diverse perspectives on these issues.

- Read and become informed on the history of Canada's Aboriginal peoples to better understand the current context. (Some readily available online resources are included in the reference list. ${ }^{12,16-18}$ )

- Bear witness to the facts of history and acknowledge that effects are still deeply felt today by all.

- Become culturally competent, with an understanding of historical legacy and current challenges that impact mental health in some Aboriginal communities. The Indigenous Physicians Association of Canada and the Royal College of Physicians and Surgeons of Canada have prepared basic training materials in cultural safety.

- Remember there is not a single pan-Aboriginal identity. Learn about the issues but be open to becoming acquainted with the large diversity of Aboriginal communities and with individuals with their own personal stories.

- Provide mental health services in culturally responsive ways and working respectfully within Aboriginal frameworks of mental wellness. Given the history of trauma and high level of adversity experienced by some First Nations people, a "trauma-informed approach" to mental health care, "based on compassion, placing priority on a trauma survivor's safety, choice, and control" is recommended by the 2015 First Nations Mental Wellness Continuum Framework. ${ }^{16}$ Yet caution must also be taken in perpetuating cultural stereotypes.

- Engage in respectful collaborations with traditional healers and knowledge holders.

- Acknowledge that local indigenous knowledge must guide the development of relevant mental health programs. There is much that Western mental health professionals can learn from some of the innovative, comprehensive and humanistic approaches to mental wellness and mental health care delivery that have been developed in some Aboriginal communities.

- As a practising psychiatrist, consider serving Aboriginal communities to address lack of services and long wait lists, preferably within the community itself. For early-career psychiatrists interested in social justice and cultural diversity, this may be a rewarding opportunity. (Note: DSM-5 contains a semi-structured interview, the Cultural Formulation Interview, which is a 16-item questionnaire designed to tap into cultural topics for clinicians to consider in patient assessment, diagnosis and treatment. ${ }^{19}$ )

- Support Aboriginal mental wellness workers in navigating and collaborating with mental health services.

- Encourage and actively support the training of young Aboriginal health professionals.
- Support and lobby for cooperation among federal, provincial and territorial governments to provide sustainable, dedicated funding for clinical mental health services in Aboriginal communities.

Affiliations: Co-editors in chief, JPN (Boksa, Joober); Department of Psychiatry, McGill University, Montreal, Que., Canada (Boksa, Joober, Kirmayer).

Competing interests: See jpn.ca/about/ for R. Joober. No other competing interests declared.

\section{References}

1. Honouring the truth, reconciling for the future: summary of the Final Report of the Truth and Reconciliation Commission of Canada. Truth and Reconciliation Commission of Canada; 2015. Available: www.trc.ca/websites/trcinstitution/index.php? $\mathrm{p}=890$ (accessed 2015 Sept. 23).

2. Kirmayer LJ, Brass GM, Tait CL. The mental health of Aboriginal peoples: transformations of identity and community. Can J Psychiatry 2000;45:607-16

3. Department of the Interior. Annual Report for the year ended 30th June, 1876 (Parliament. Sessional Papers, No. 1877;11:xiv.

4. National Archives of Canada, Record Group 10, vol 6810, file 4702-3, vol 7, pp. 55 (L-3) and 63 (N-3).

5. Kirmayer LJ, Gone JP, Moses J. Rethinking historical trauma. Transcult Psychiatry 2014;51:299-319.

6. Bombay A, Matheson K, Anisman H. The impact of stressors on second generation Indian Residential School survivors. Transcult Psychiatry 2011;48:367-91.

7. Elias B, Mignone J, Hall M, et al. Trauma and suicide behaviour histories among a Canadian indigenous population: an empirical exploration of the potential role of Canada's residential school system. Soc Sci Med 2012;74:1560-9.

8. Bombay A, Matheson K, Anisman H. The intergenerational effects of Indian residential schools: implications for the concept of historical trauma. Transcult Psychiatry 2014;51:320-38.

9. Currie CL, Wild TC. Adolescent use of prescription drugs to get high in Canada. Can J Psychiatry 2012;57:745-51.

10. Fischer B, Argento E. Prescription opioid related misuse, harms, diversion and interventions in Canada: a review. Pain Physician 2012;15(Suppl):ES191-203.

11. Currie CL, Wild TC, Schopflocher DP, et al. Illicit and prescription drug problems among urban Aboriginal adults in Canada: the role of traditional culture in protection and resilience. Soc Sci Med 2013; 88:1-9.

12. Feathers of Hope, a First Nations Youth Action Plan. Provincial Advocate for Children \& Youth. Toronto, ON; 2014. Available: http ://digital.provincialadvocate.on.ca/i/259048-foh-report (accessed 2015 Sept. 24).

13. Lemstra $\mathrm{M}$, Rogers $\mathrm{M}$, Moraros J, et al. Risk indicators of suicide ideation among on-reserve First Nations youth. Paediatr Child Health 2013;18:15-20.

14. Kirmayer L, Brass G, Holton T, et al. Suicide among Aboriginal people in Canada Ottawa: Aboriginal Healing Foundation 2007. Available: www.ahf.ca/publications/research-series (accessed 2015 Sept. 24).

15. Chandler MJ, Lalonde CE. Cultural continuity as a hedge against suicide in Canada's First Nations. Transcult Psychiatry 1998;35:191-219.

16. First Nations Mental Wellness Continuum Framework. Health Canada; 2015. Available: http://health.afn.ca/uploads/files/24 -14-1273-fn-mental-wellness-framework-en05_low.pdf (accessed 2015 Sept. 24).

17. University of Manitoba National Centre for Truth and Reconciliation. Available: http://umanitoba.ca/centres/nctr/index.html (accessed 2015 Sept. 24).

18. University of British Columbia: Indigenous Foundations. Available: http://indigenousfoundations.arts.ubc.ca/ (accessed 2015 Sept. 24).

19. Lewis-Fernandez R, Aggarwal N, Hinton L, et al., eds. DSM-5 Handbook on the Cultural Formulation Interview. Washington, DC: American Psychiatric Press; 2015. 